\title{
SOLERA DEMONSTRATOR OF SMALL SCALE SOLAR HEATING AND COOLING SYSTEM IN INES OFFICE BUILDING
}

\author{
David Chèze ${ }^{\mathrm{a}, *}$, François Boudéhenn ${ }^{\mathrm{a}}$, Philippe Papillon ${ }^{\mathrm{a}}$, Daniel Mugnier ${ }^{\mathrm{b}}$, Tomas Núñez \\ ${ }^{a}$ CEA LITEN Institut National de l'Energie Solaire: INES, Le Bourget du Lac (France) \\ ${ }^{b}$ TECSOL, Perpignan (France) \\ ${ }^{c}$ Fraunhofer ISE, Freiburg (Germany)
}

\section{Introduction}

This work was done in the SOLERA project (http://www.solera-project.eu), Sixth EU Framework Program (FP6), co-funded by EC and coordinated by Fraunhofer ISE. It started in November 2007 and will stop in November 2011. The goal of the SOLERA project is to install, operate and evaluate three different solar cooling systems of different sizes. We give here an overview of the design and experimental results of the system. The system of the subgroup 3

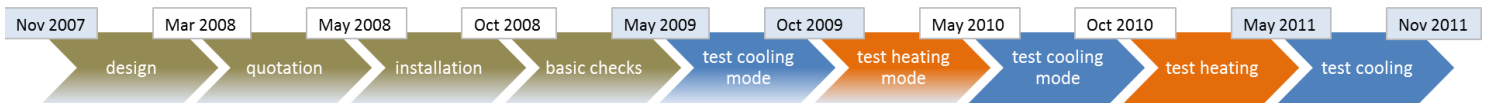

Figure 1: Time line of the system design and operation

is installed in Chambéry in the French Alps and is committed to refresh in summer and to heat in winter a small office building occupied by INESs employees. The design of the whole system was based on standard components from southern Europe subgroup 3 industrial partners CIAT (CIAT group, France), CLIPSOL (GDF SUEZ group, France) and ROTARTICA (FAGOR group, Spain) to evaluate the feasibility of delivering a solar package within objective costs. We brought special attention to the controller design in order to achieve the best global performance of the whole system. Thanks to more than two years long monitoring period (see figure 1) we optimized the control strategy and we want provide a reliable refreshing experience of solar system to the public place.

\section{System design}

The design of the system was usually drived by dimensionning heat and cool load and by requirement of 3 operating modes : direct heating, heat pump heating, in order to maximize the use of solar energy along the year and improve thereafter the annual productivity of the collector field. There's no hot water demand in this office building while the system has to be able to provide it for general use.

The thermal load in table 1 for one room was estimated from office building plans since it was not already erected at the begining of the project : there are 3 rooms in the building to connect to the system for heating and cooling during whole year that are requiring a maximal cooling power of $4.5 \mathrm{~kW}$ and to a maximal heating power of $9 \mathrm{~kW}$ which meets specifications of the hereunder proposed chiller.

The main investigations targets required by the project were:

- Small scale absorption chiller $\left(\mathrm{LiBr}-\mathrm{H}_{2} \mathrm{O}\right) 045$ from ROTARTICA with nominal cooling power of 4,5 kW, low regeneration temperature $75-105^{\circ} \mathrm{C}$ that can be reached by usual flat plate solar collectors while still showing reasonnable efficiency.

\footnotetext{
${ }^{*}$ Corresponding author

Email address: david.cheze@cea.fr (David Chèze)
} 
Table 1: Estimated thermal load for one of the three identical rooms connected to SOLERA installation

\begin{tabular}{|c|c|c|}
\hline Area & Height & People inside \\
\hline $21 \mathrm{~m}^{2}$ & $2.5 \mathrm{~m}$ & 2 \\
\hline Winter set temp. & Heat loss & Heating power \\
\hline $19^{\circ} \mathrm{C}$ & $1107 \mathrm{~W}$ & $1500 \mathrm{~W}$ \\
\hline Summer set temp. & Total gains & Cooling power \\
\hline $25^{\circ} \mathrm{C}$ & $2930 \mathrm{~W}$ & $3000 \mathrm{~W}$ \\
\hline
\end{tabular}

- Flat plate collectors $T G D$ from CLIPSOL, collector field sized to $30 \mathrm{~m}^{2}$ for heating space and driving the thermal absorption chiller.

- Integrated system preferred for Solar Combined System (SCS, heating space and domestic hot water supply), CombiRSD 120 from CLIPSOL embedding 400L buffer tank, 12kW auxiliary electric boiler and the controller for the whole system.

- Ground loop heat rejection exchanger, oversized to allow heat exchange performance studies. Main advantage of this kind of exchanger is the null electrical parasitic consumption in comparison with outside fan coils dryor wet-coolers.

- Distribution design low heating temperature $\left(38 / 45^{\circ} \mathrm{C}\right)$ to maximize direct use of solar energy in winter and to allow medium operating distribution temperature $\left(13 / 18^{\circ} \mathrm{C}\right)$ in cooling mode.

- Classical occupation scenario for office building : 7h00-19h00 from monday to friday, no occupation during the weekend.

- No use of boiler hot backup on the chiller's generator during cooling season.

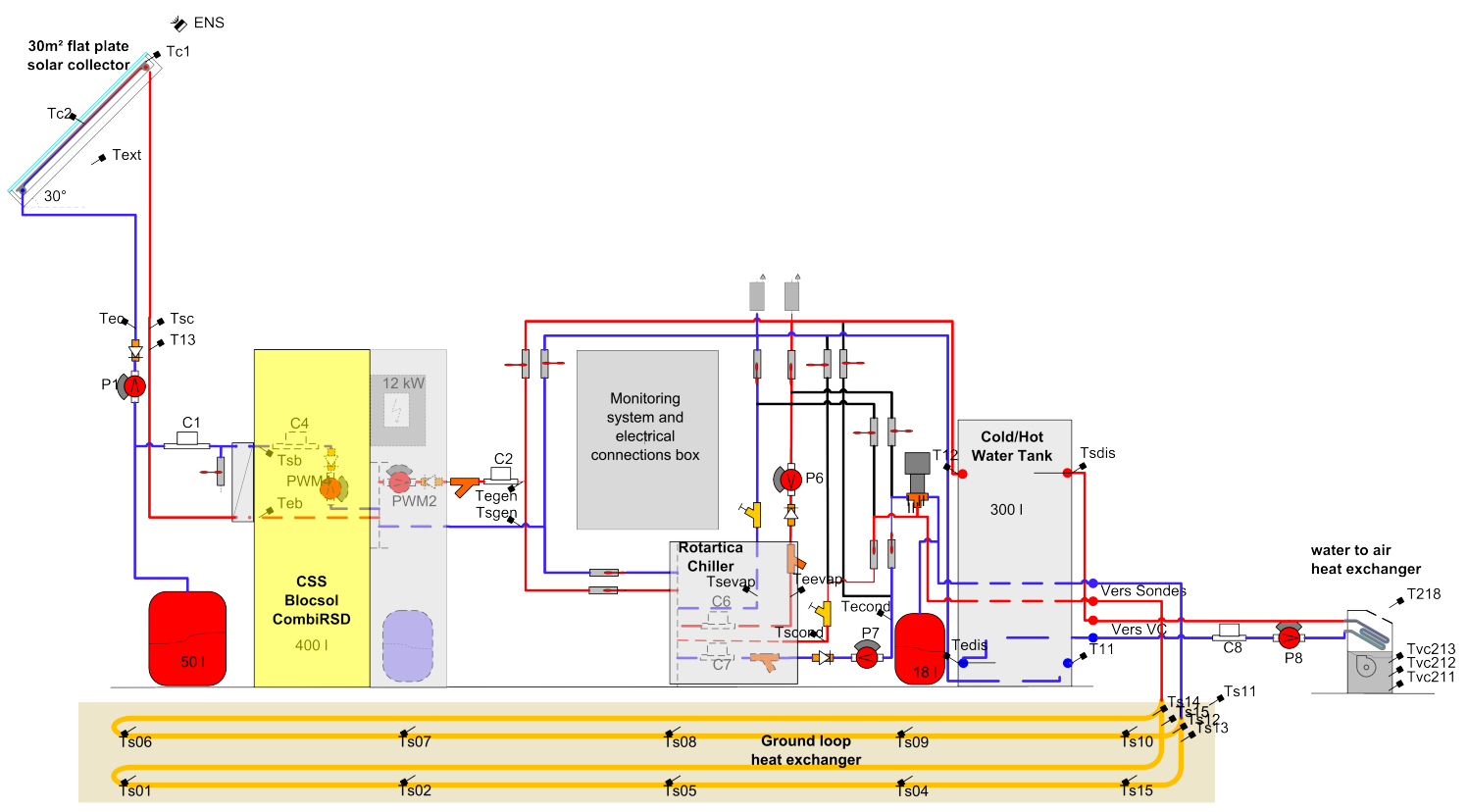

Figure 2: Schematic of the main operating components of the installation, ie solar collectors, CSC, controller and monitoring system, absorption chiller, hydraulic piping and motorized valves, distribution storage tank, distribution loop and heat rejection ground loop 


\section{System installation}

The concrete system is splitted in four installation areas connected to INES's office building : solar collector field, ground work, technical station and hydraulic distribution to fan coil in the three office rooms (see figure 3, 4, 5 and 6 respectively).

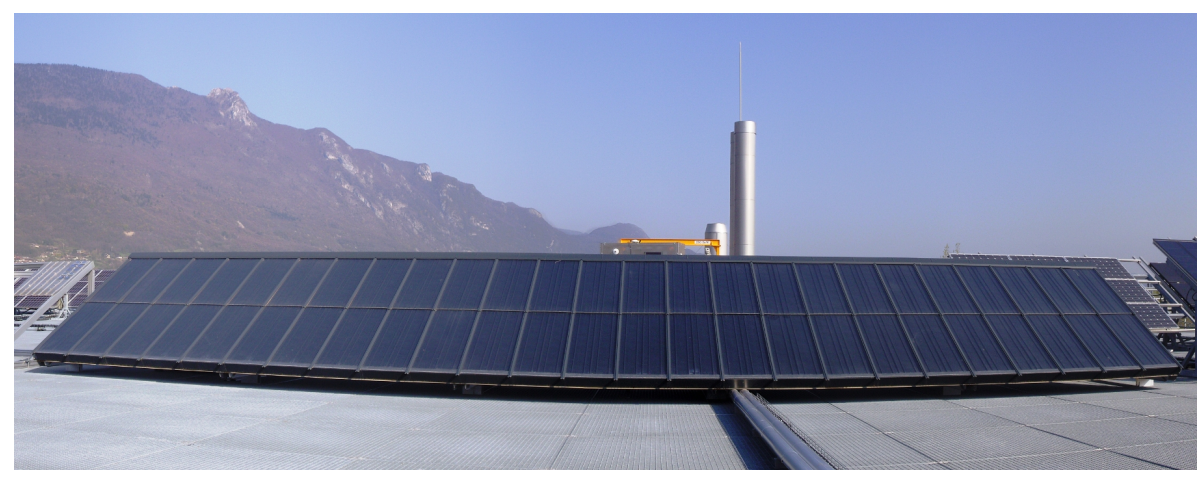

Figure 3: $30 \mathrm{~m}^{2}$ flat plate solar collector field on the top roof

Since the building was already built when the ground was buried to install the ground heat exchanger loop, it was necessary to make a hole in the existing wall : this solution was cheaper than to drill the foundations but require to insulate the external path between the ground and the building to avoid freezing during the winter since the whole circuit is filled with water, except solar collector loop. The ground heat exchanger itself was made of $2200 \mathrm{~m}$ long pipe of cross linked polyethylene 16/20 diameter and arranged into 2 maps of $1 \times 25 \mathrm{~m}$ then buried in the earth close to the office building, at $0.75 \mathrm{~m}$ and $1.1 \mathrm{~m}$ depth. 15 sensors are inserted to monitor both fluid and ground temperatures in various locations along this loop.

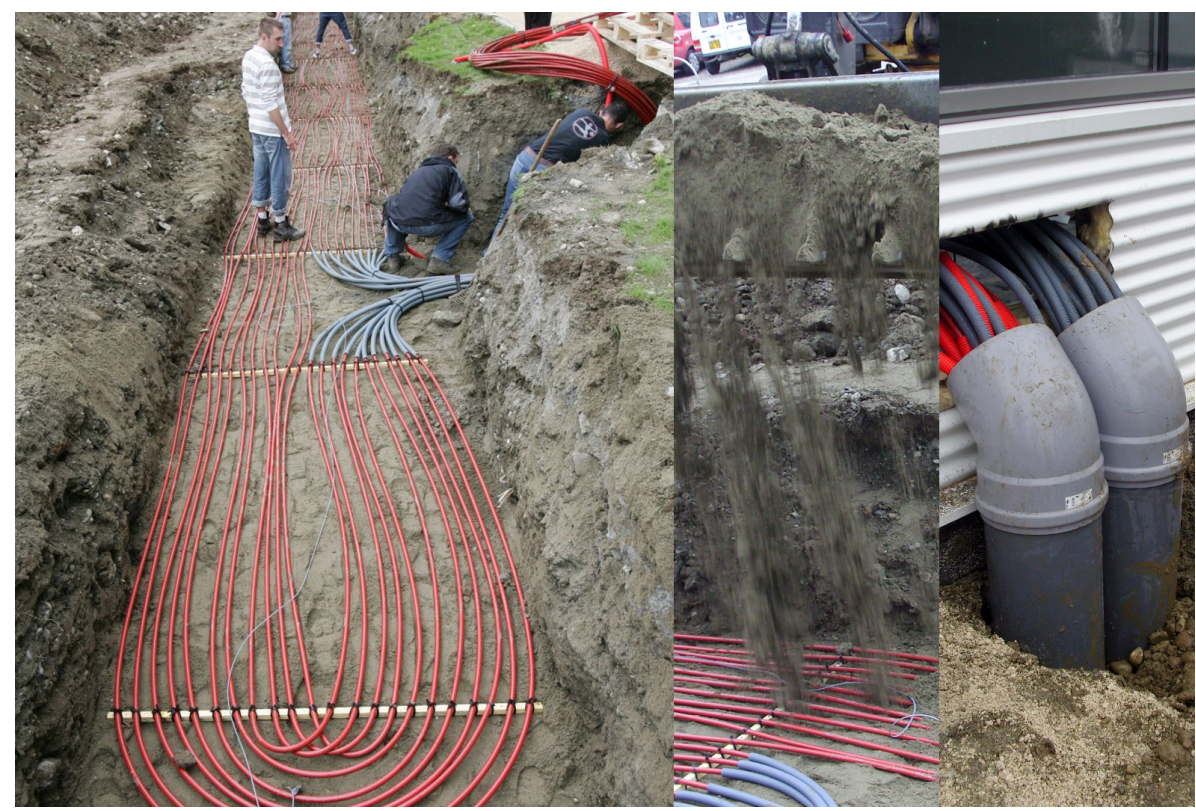

Figure 4: Focus on the main steps of the ground heat exchanger realization

In the technical station, motorized 2-ways valves have been replacing originally manual ones so that controler can switch from heat pump mode to direct heating mode in winter when running the boiler. The switch criteria is based 
on outside temperature, power demand from the distribution loop and thermal performance of the chiller in thess operating conditions.

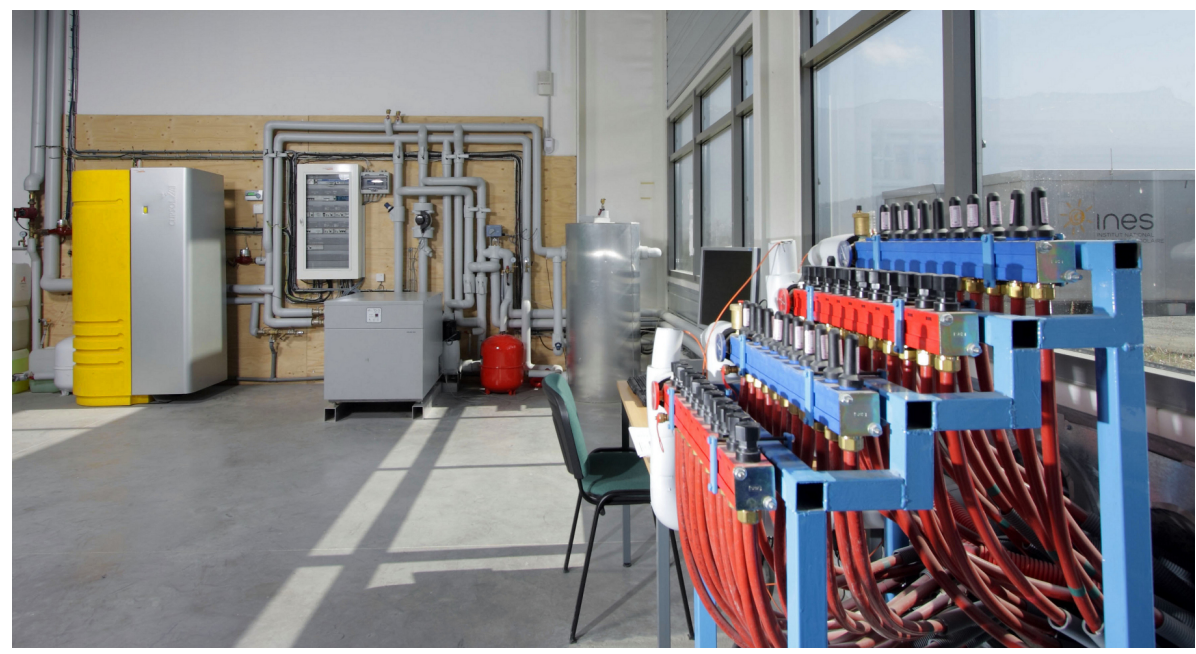

Figure 5: View of operating installation - CLIPSOL's SCS, absorption chiller, cold storage tank and ground loop collector in the technical area

The hydraulic distribution integrates a 300L water buffer tank feeding 6 fan coils high efficiency energy Coadis HEE from CIAT, two pieces installed in each of the three room connected to the system. The rooms are located at $15 \mathrm{~m}$ of the buffer tank.

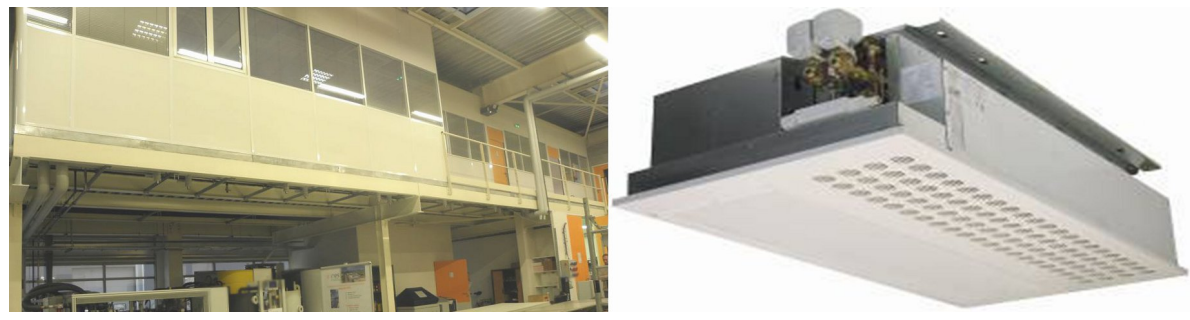

Figure 6: View of the 3 rooms and the high efficiency fan coil

\section{Costs overview}

Costs included in items of table 2 : main subset components, pipework, insulation, installation's work. It should be noticed that heat rejection circuit cost's share is as high as these of technical station or roof work : this prototype of ground heat exchanger was laboratory made, assembled and installed. Processes were not optimized as it would be by professional people. It is assumed that this costs could be drastically reduced by industrial partners when redefining the whole system as a package including pipework,valves and pumps between CSS and chiller, as well as pre-manufacturing the ground heat exchanger.

\section{Numerical simulation}

The absorption chiller and ground loop as TRNSYS components models were developped by INES and parameters set was successfully fitted with experimental data as shown in figure 7. Absorption chiller Rotartica was modeled 
Table 2: Cost subsets and distribution for Solera demonstrator

\begin{tabular}{|c|c|c|}
\hline Subsets & Full costs (k€) & Costs distribution \\
\hline Roof work - solar collector field & 20.9 & $26 \%$ \\
Technical station - SCS \& chiller & 21.4 & $27 \%$ \\
Heat rejection circuit & 20.5 & $26 \%$ \\
Hydraulic distribution circuit & 9.2 & $11 \%$ \\
Data acquisition \& control - wiring - commissionning & 8.2 & $10 \%$ \\
Total & $\mathbf{8 0 . 3}$ & \\
\hline
\end{tabular}

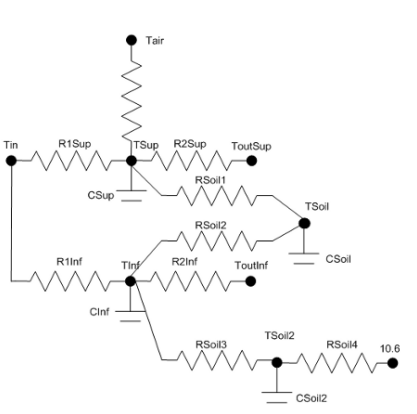

(a) Electrical analogy description used to simulate ground behaviour

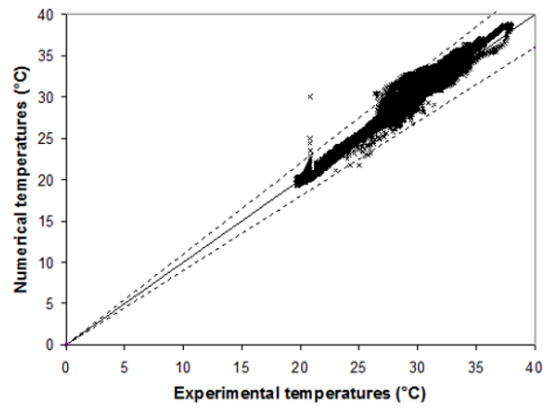

(b) Coherence of experimental powers measured at Generator, Evaporator, AbsorberCondenser of Rotartica chiller and absorption chiller model output powers in various operating conditions - data obtained from AbClimSol, french national research project PREBAT 2007

Figure 7: Validation of numerical models

according to Ziegler's method (Ziegler et al., 1999) while ground heat exchanger was modeled through our own electrical analogy. These empirical models were preferred to detailed ones for the sake of simulation speed up.

Additionnally a controller model was also developped and linked with previously cited INES own models and standard TRNSYS's models: it allows to build a full system simulation and lead to a simplified dimensionning tool for end-users, which is a public deliverable of SOLERA project and will be available from november 2011 on SOLERA's website.

\section{System operation}

\subsection{Monitoring and tools}

The system is monitored according to IEA Task 38 recommendations (Sparber et al., 2008). Monthly data analysis and performance criteria calculation according to reference defined in MéGaPICS (Le denn et al., 2011) french national research project is achieved since May 2009. A summary of the results is given in table 3 .

A logbook is used for tracing every actions or observed dysfunctionments what is useful while trying to explain a posteriori performance indicators variations. Since the installation is dedicated to run over a long period and already ran for more than two years, there's a lot of experimental data to process : we develop in 2011's spring a software written in Scilab language for reliable automated energy balances and performance criteria computation.

Moreover since we observed that monitoring, controling troubleshootings or components failures can be tricky to detect, a second software written in Scilab was developed for this purpose by Simon Thouin, engineer graduate student : the program is lightweight since it may be embedded in solar controlers in the future and is computing online several performance criteria and checking normal behaviour predefined rules. It is currently in test since August 2011 on the Solera system. 
Table 3: Results summary of 2 annual periods from May 2009 to May 2011, indicators names from Le denn et al. (2011)

\begin{tabular}{|c|c|c|c|c|c|}
\hline year / [kWh] & Qsol & Q1 solar & Q2 Boiler & Q3 heat. load & Q6 chill. gen. \\
\hline 2009 - 2010 & 42949 & 10115 & 1963 & 2545 & 4397 \\
2010 - 2011 & 35426 & 7764 & 4987 & 6519 & 2305 \\
\hline Q7 chill. eva. & Q10 cool. load & total load & Eaux & ESU & \\
\hline 3057 & 3250 & 7219 & 1383 & 6091 & \\
1667 & 1662 & 8817 & 764 & 5366 & \\
\hline & & & & & \\
\hline year / [] & PER & SPF & SPF hot & SPF cold & COPeleccold \\
\hline 2009 - 2010 & 0.65 & 1.68 & 1.26 & 2.42 & 2.61 \\
2010 - 2011 & 0.53 & 1.36 & 1.24 & 2.27 & 2.51 \\
\hline COPelechot & COPelec & fsavth & COPthChill & R stock hot & R stock cold \\
\hline 3.80 & 3.04 & 0.48 & 0.70 & 0.57 & 1.06 \\
6.30 & 4.65 & 0.30 & 0.72 & 0.69 & 1.00 \\
\hline R sol U & COPelecSol & FS & R collector & Comfort & \\
\hline 0.14 & 4.40 & 0.88 & 0.24 & 0.96 & \\
0.15 & 7.02 & 0.61 & 0.22 & 0.97 & \\
\hline
\end{tabular}

\subsection{Results discussion}

In July 2010 a new building was erected in front of the heated/cooled rooms and top of every buildings was covered by a metallic grid causing noticeable solar shading : it is confirmed by table 3 that is showing significant increase of heating load during winter season between 2010 and 2011 and decrease of cooling load between summer season 2009 and 2010. During last one year period Usable Solar Productivity (defined as ESU divided by solar collector aperture area) decreases from 203 to $178 \mathrm{kWh} / \mathrm{m}^{2}$, what can mainly be explained by this cooling load reduction.

An additionnal hydraulic connections insulation was applied in September 2010 and controller optimization in cooling mode (reduced cycling and parasitic consumption in low cooling demand conditions as in holidays or weekend time, August 2010) as in heating mode (design heating temperature delivered to the fan coils adjustments, February 2011): we can see through auxiliairy consumption reduction Eaux and increase of efficiency of hot storage tank RstockHot and of global COPelec in table 3 that these modifications improve the performance and reliability of the system.

Solar collector efficiency Rcollector is decreasing at a low level during last period : it is a consequence of cool load reduction combined with new protection algorithm of installation in case of room vacancy which let the temperature rise to more than $100^{\circ} \mathrm{C}$ in the collector to reduce its efficiency and to avoid to load the hot storage tank at high temperature while there's no thermal energy demand to the system.

Looking at value of COPthChill indicator in table 3 we can say that chiller performances integrated in SOLERA system are reliable.

COPelec or PER indicators are not favourable for Solera because of electric boiler in comparison with gaz fired one for example. We noticed here that there are indicators for installation driving improvement and indicators for multiple installations performances comparison.

From figure 8 we can see monthly evolution of the system over the last two years and looking at COPelecSol and Rsol indicators shows that modifications of control strategy improve solar efficiency of the system in winter as expected and decrease in summer because of the heavy load reduction which lead to low solar performances behaviour of protection already discussed above.

\section{Conclusion}

The system requires only very reduced maintenance effort (only monthly check of pressure inside the hydraulic distribution and collector loop) while exhibiting a good quality of service (see Comfort indicator of the users in the 


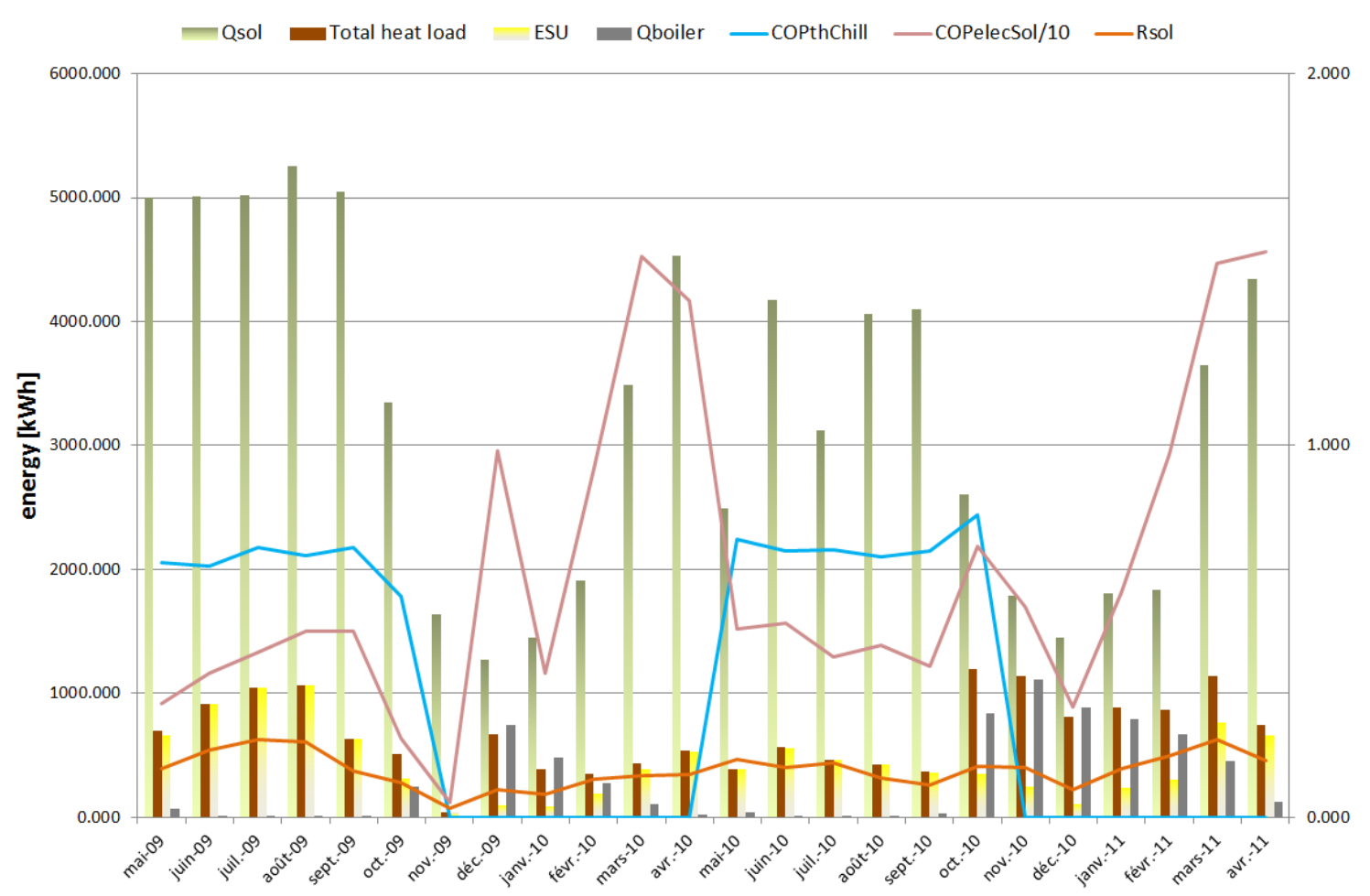

Figure 8: Evolution of the system performances over 2 years, indicators names from Le denn et al. (2011)

table 3). That's encouraging INES to run the installation and collect data even after the end of the program, especially for critical components aging evaluation, long term performance evaluation and automatic failure detection algoritm improvement. It is planned to extend the hydraulic disctribution to other rooms in order to compensate the cooling load reduction because of front shading building. Through this demonstration operation partners learned to drive the solar heating/cooling installation to reliability thanks to indicators which are providing a rich synthetic view of the system.

\section{References}

Le denn, A., Boudéhenn, F., Lucas, P., Papillon, P., Nowag, J., Kaemerlenn, Letellier, N., Gay, 2011. First results of MeGaPICS method towards Solar Heating and Cooling installation performance guarantee. Proceeding, 4th International Conference Solar Air Conditioning

Sparber, W., Thuer, A., Besana, F., Streicher, W. and Henning, H.-M., 2008. Unified monitoring procedure and performance assessment for solar assisted heating and cooling systems. http://www.iea-shc.org/publications/downloads/task38-Unified_monitoring.pdf

Ziegler, F., Hellmann, H.-M. \& Schweigler, C., 1999. An approximative method for modeling the operating characteristics of advanced absorption chillers. Proceeding, 20th International Congress of Refrigeration, IIR/IIF, Sydney. 